\title{
A Spialia orbifer (Hübner, 1823) és a S. sertorius (Hoffmannsegg, 1804) terepi elkülönítése (Lepidoptera: Hesperiidae)
}

Differentiation of Spialia orbifer (Hübner 1823) and S. sertorius (Hoffmannsegg, 1804) in the field (Lepidoptera: Hesperiidae)

\author{
Gergely Péter
}

Citation. Gergely P. 2021: A Spialia orbifer (Hübner, 1823) és a S. sertorius (Hoffmannsegg, 1804) terepi elkülönítése (Lepidoptera: Hesperiidae) | Differentiation of Spialia orbifer (Hübner 1823) and S. sertorius (Hoffmannsegg, 1804) in the field (Lepidoptera: Hesperiidae). - Lepidopterologica Hungarica 17: 15-20.

Abstract. The number of dark stripes in forewing fringe is often used for distinguishing these two species. The calculated specificity of this feature is between only 85 and $94 \%$, therefore unsuitable for discrimination. The reliable marker is the shape of white spots on hind-wing underside.

Keywords. Spialia orbifer, S. sertorius, identification, forewing fringe

Author's address. Gergely Péter | 2014 Csobánka, Hegyalja lépcső 4. |

E-mail: pgergely@alexmed.hu

Summary. Spialia sertorius is a West-European, Atlantic species; its range extends to the East in Austria, Hungary, and Slovakia. Spialia orbifer is a south-eastern species, which is rather common in Hungary and the Balkans. The area of these two species overlaps in the above-mentioned countries. Since both species are variable, the field identification can be difficult, and therefore, reliable markers are needed to distinguish them. According to the Hungarian textbook by Gozmány (1968), the number of stripes (7 or 5-6) in the fringe of forewing upper side has been suggested as a reliable marker for differentiation. Examination of forewing upper sides of 50 Spialia sertorius and those of 61 Spialia orbifer, for the number of dark stripes in the fringes, a specificity of $94 \%$ (sertorius-orbifer) and $85.2 \%$ (orbifer-sertorius) was found. It was concluded that the number of stripes in forewing fringe is not a reliable marker for differentiation of these two species. According to available literature, the reliable marker is the shape of the white spots, in particular the discal spot in hindwing underside.

\section{Bevezetés - Introduction}

A két faj taxonómiai elkülönítése ugyan még vita tárgya, Lorkovic (1973) azonban elég egyértelmüen bizonyította, hogy valóban két különálló fajról van szó. Elterjedésük elkülönül, Magyarország éppen e két faj nyugati és északi határát képezi.

A nyugati törpebusalepke (Spialia sertorius Hoffmannsegg, 1804) nyugat-európai, atlantikus elterjedésü, melegkedvelö faj, amely az Alpok déli vonulatain felhatol a havasi zónába is. Tölünk északra Szlovákiában a Tátra déli vonulatai mentén keletre hatol. Hazánkban van az elterjedésének keleti határa, némi átfedésben a hozzá nagyon hasonló kerekfoltú törpebusalepkével (Spialia orbifer Hübner, 1823), amely elterjedésének nyugati határa Alsó-Ausztriáig (Höttinger 2001), északi határa pedig DélSzlovákiáig (Slamka 2004) terjed.

A Spialia orbifer közép- és dél-európai faj; a Kárpát-medencétől a Balkánon át Törökországig, a Közel-Keletig, illetve a Tien-Sanig húzódik elterjedésének a határa. 


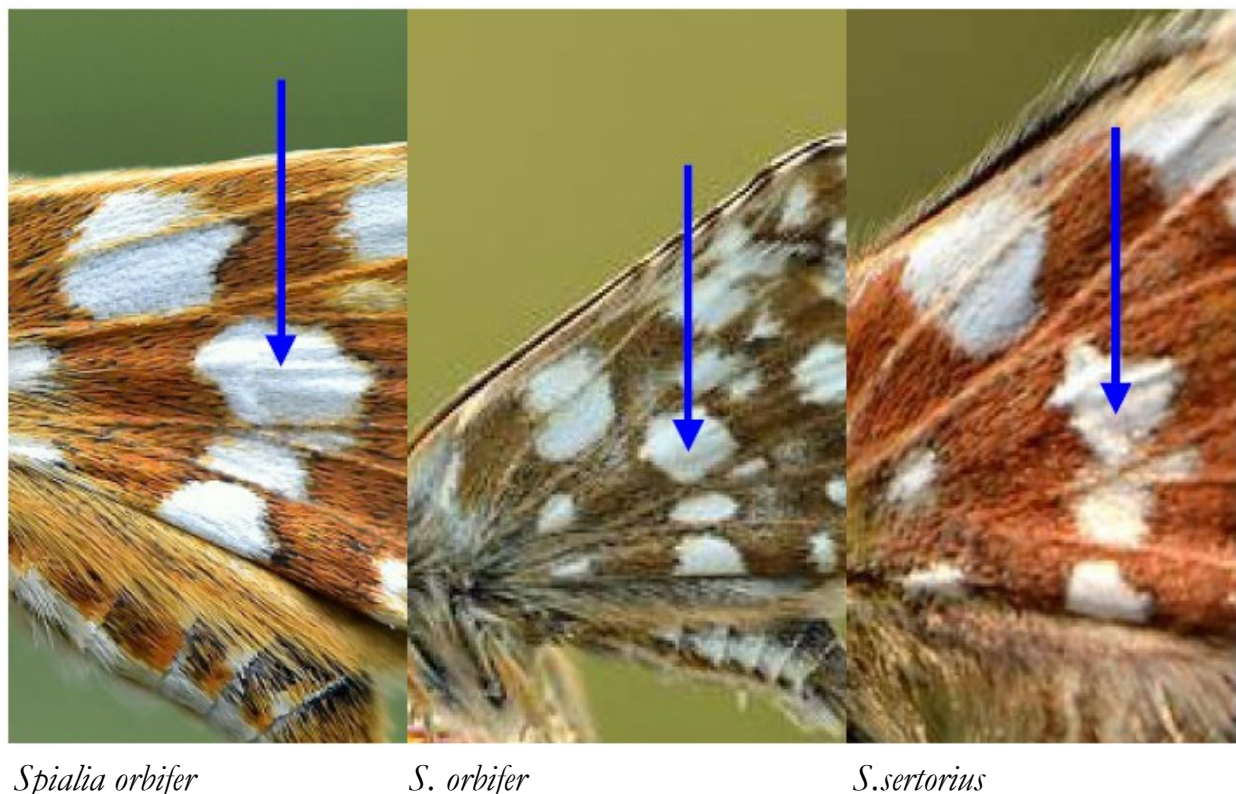

1. ábra. A két Spialia faj hátulsó szárnyának fonákja. A S. orbifer foltjai, különösen a sejtvégi foltja kerekded (nyíl), míg a $S$. sertorius sejtvégi foltja szögletes, csücskös (nyíl).

Figure 1. Hind-wing undersides of the two Spialia species. The discal spot of S. orbif$e r$ is rounded (mark), that of $S$. sertorius is ragged (mark).

Magyarországon a szárazabb füves területeken (sztyeppréteken) található. Sokfelé megtalálható, időnként egyes élőhelyein viszonylag gyakori is lehet (Gergely et al. 2018).

A Spialia sertorius előfordulásáról recens adatok elsősorban a nyugati határszélről, Fertőrákosról (Sáfián et al. 2006) vannak, ahol stabil populációja tenyészik. Korábbi időkből vannak szórvány megfigyelések a Dunántúl több pontjáról és a Bükkből, illetve Aggteleki-karsztról (Fazekas 1986; Varga 1989).

Mindkét faj eléggé változatos, ezért a morfológiai jegyek alapján, különösen a terepen, a pontos diagnózis nem feltétlenül állapítható meg. A Spialia sertorius hazai adatai - a bizonyító példánnyal alátámasztott adatokon kívül - gyakorlatilag teljesen bizonytalanok (pl. Mosonmagyaróvár, Keszthelyi-hegység, Aggtelek), sok esetben valószínüleg a Spialia orbifer fajra vonatkoznak, amely igen változékony, előfordulnak erősen vöröses fonákú (pl. 5. ábra) példányok is (Sáfián et al. 2006).

A hazai irodalomban eléggé elterjedt a Gozmány (1968) határozójában megadott jellemző: a Spialia orbifer „elülső szárnyának külső szegélyén a rojtot 7 fekete csík vágja ketté”, míg a Spialia sertorius esetén ,5-6 fekete csík vágja ketté”. A két faj hátulsó szárnyának csak a színe (,olajzöld”, ill. ,piros vagy vörhenyes”) van. A hazai irodalomban eléggé elterjedt a Gozmány (1968) határozójában megadott jellemző: a Spialia orbifer ,elülső szárnyának külső szegélyén a rojtot 7 fekete megadva a határozóban, a foltok alakjáról nem esik szó. Slamka (2004) megemlíti, hogy a Spialia sertorius esetén az $\mathrm{M}_{2}$ ér végén lévő fekete csík hiányzik, vagy csak gyengén mutatkozik - míg a Spialia orbifer esetén jól (esetleg csak gyengén) látható. Ezeket az adatokat számos szerző átvette (pl. Gergely et al. 2018; Szabóky 2020), míg a legújabb hazai határozóban (Tóth 2019) már nem szerepel. 
1. táblázat. Diagnosztikus markerek | Table 1. Diagnostic Markers

\begin{tabular}{|l|l|l|}
\hline Szerzö(k) & rojt-csík & fonák-folt \\
\hline Gozmány L. & + & - \\
\hline Lafranchis T. & - & + \\
\hline Tolman T. \& Levington R. & - & - \\
\hline Haahtela T. et al. & - & + \\
\hline Macek J. et al. & - & + \\
\hline Slamka F. & \pm & + \\
\hline Rákosy L. & - & + \\
\hline
\end{tabular}

2. táblázat. Az elülső szárny rojtjainak csíkjai | Table 2. Stripes of fore-wing fringe

\begin{tabular}{|c|c|c|c|}
\hline Elülső szárny & 5-6 csík & 7 csík & Bizonytalan \\
\hline \multicolumn{4}{|l|}{ Spialia sertorius } \\
\hline Rowlings M. ${ }^{1}$ & $\begin{array}{l}21 / 23 \\
\text { (Svájc, Franciaország, } \\
\text { Spanyolország, }\end{array}$ & $0 / 23$ & $\begin{array}{l}2 / 23 \\
\text { (Olaszország, } \\
\text { Svájc) }\end{array}$ \\
\hline Lepiforum $^{2}$ & 7/8 (Németország) & 1/8 (Svájc) & $0 / 8$ \\
\hline Gibbons R. ${ }^{3}$ & $\begin{array}{l}19 / 19 \\
\text { (Franciaország) }\end{array}$ & $0 / 19$ & $0 / 19$ \\
\hline Összesen & $47 / 50(\mathbf{9 4 \%} \%)$ & $1 / 50(2 \%)$ & $2 / 50(4 \%)$ \\
\hline \multicolumn{4}{|l|}{ Spialia orbifer } \\
\hline Rowlings M. ${ }^{4}$ & 2/22 (Görögország) & $\begin{array}{l}18 / 22 \\
\text { (Görögország, Szer- } \\
\text { bia) } \\
\end{array}$ & $\begin{array}{l}\text { 2/22 } \\
\text { (Görögország) }\end{array}$ \\
\hline Gergely Péter & 1/29 (Magyarország) & $27 / 29$ & $1 / 29$ \\
\hline Lepiforum $^{5}$ & 1/10 (Görögország) & $\begin{array}{l}\text { 7/10 (Görögország, } \\
\text { Románia, Bulgária, } \\
\text { Örményország) }\end{array}$ & $\begin{array}{l}\text { 2/10 } \\
\text { (Görögország) }\end{array}$ \\
\hline Összesen: & $4 / 61(6,5 \%)$ & $52 / 61(\mathbf{8 5 , 2 \%})$ & $5 / 61(8,2 \%)$ \\
\hline
\end{tabular}


Érdekes módon a csíkokra vonatkozó adat nem található meg a legtöbb határozókönyvben (Tolman \& Levington 1997; Lafranchis, 2004; Haahtela et al. 2011; Rákosy 2013; Macek et al. 2015). Ugyanakkor a fö különbségeket a szerzők a fonák foltjainak alakjában határozták meg (lásd 1. táblázat). A Spialia orbifer hátulsó szárnyának fonákján ugyanis a foltok kerekdedek, míg a Spialia sertorius foltjai, kivált a sejtvégi folt, egyenetlen kontúrú, szögletes, csücskös.

\section{Anyag és módszer - Material and methods}

Megvizsgáltam, hogy a két faj rojt-csíkjainak száma mennyire jellemző. Ebben arra támaszkodtam, hogy a tölünk nyugatra (Svájc, Olaszország, Spanyolország és Franciaország), illetve északra (Németország) a Spialia orbifer nem fordul elö, a tőlünk délre eső régióban (Szerbia, Görögország) pedig a Spialia sertorius nem fordul elö. Vagyis az ezekről a helyekről származó fényképek biztosan a megadott fajt mutatják. A kétséges hazai eseteket a fonák foltjai alapján határoztam meg. Ötven Spialia sertorius és 61 Spialia orbifer fényképet vizsgáltam meg a rojtok számát illetően.

\section{Eredmények - Results}

Az eredményeket a 2. táblázat mutatja be. Láthatjuk, hogy a Spialia sertorius esetén az 5-6 (többnyire 6) csík az esetek 94\%-ában, a Spialia orbifer esetén a 7 csík 85,2\%-ban fordult elő. Egy svájci Spialia sertorius példány mutatott 7 csíkot (2. ábra), míg négy Spialia orbifer (egy hazai és három görögországi) példány mutatott 5-6 csíkot (3-5. ábra). Mindkét faj esetében voltak bizonytalan példányok is (5. ábra). Mindezek alapján a meghatározás specificitása 94\% (sertorius-orbifer), illetve csak 85,2\% (orbifersertorius).

\section{Következtetés - Conclusion}

Ebböl egyértelmüen következik, hogy a rojt csíkjainak száma önmagában nem megfelelő a két faj elkülönítésére. Különösen nem, ha Spialia orbifer-ek között sertorius-t próbálunk kimutatni (ez a hazai helyzet). Ugyancsak nem elegendő ehhez a fonák színe, a faj biztosan csak a fonák foltjainak alakja szerint határozható meg (lásd 1. ábra).

\section{Összefoglalás - Summary}

Az elülső szárnyrojt csíkjainak számát gyakran használják e két faj elkülönítésére. Ennek a tulajdonságnak a specificitása csak 85 és 94\% között van, ezért nem alkalmas az elkülönítésre. Egyedüli megbízható jel a hátulsó szárnyak fonákján lévő fehér foltok alakja. 

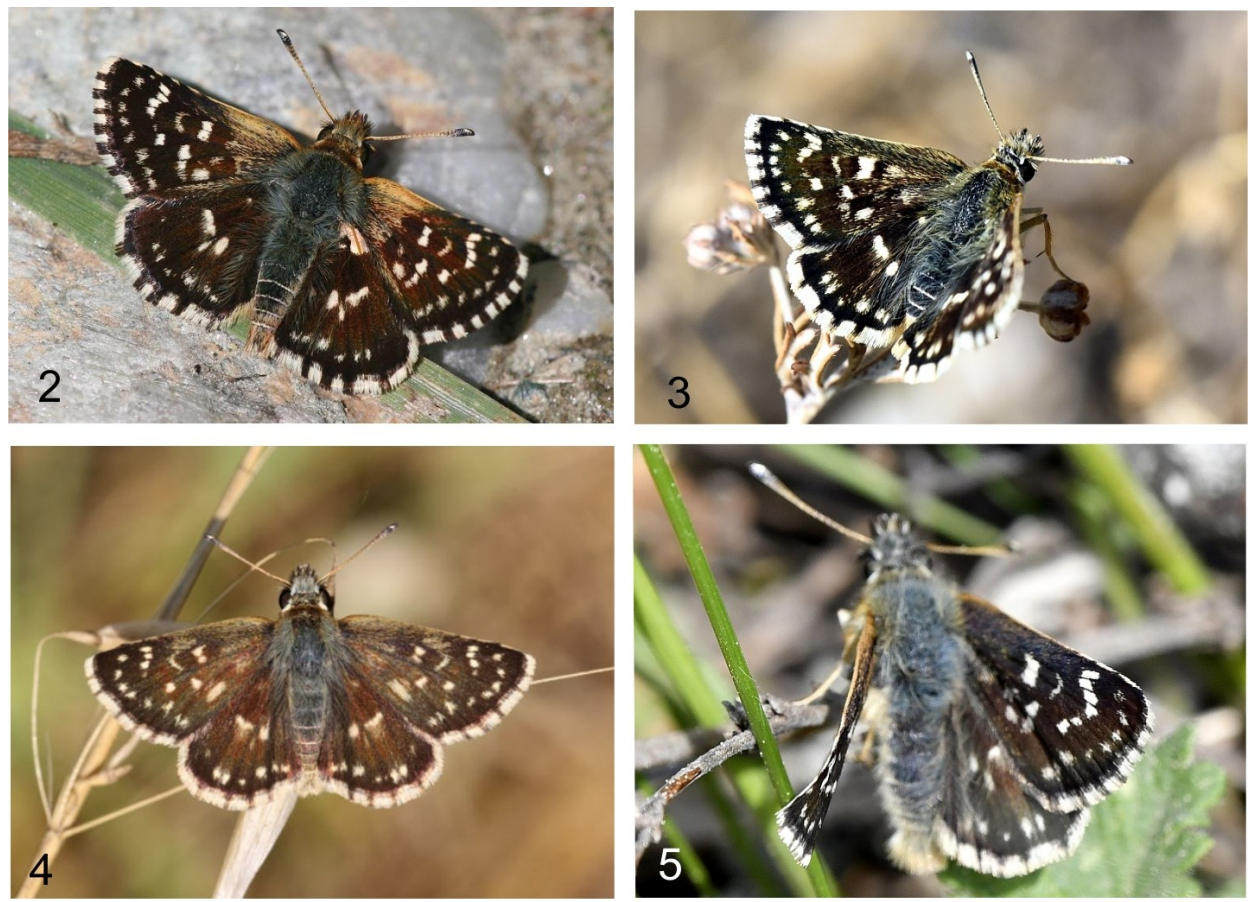

2-5. ábra. 2) Spialia sertorius (7 csík, Svájc, Wallis, Mattertal, 1700 m, 2008.07.22., Jürgen Rodeland); 3) $S$. orbifer (5-6 csík, Pomáz, Majdánfennsík, $200 \mathrm{~m}, 2015.07 .16$. Gergely Péter); 4) S. orbifer (5-6 csík, ENNyGörögország, 2016 július, Matt Rowlings); 5) S. orbifer (bizonytalan, Vértes, Gánt-Gránás, $220 \mathrm{~m}$, 2018.04.27., Gergely Péter); 6) a 4. képen ábrázolt lepke fonákja.

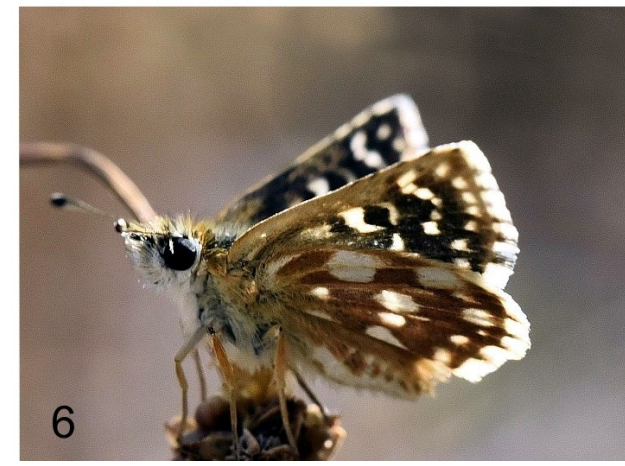

Figures 2-6. 2) Spialia sertorius (7 stripes, Switzerland); 3) S. orbifer (5-6 stripes, Pomáz, Hungary); 4) S. orbifer (5-6 stripes, Greece); 5) S. orbifer (uncertain, Vértes Mts., Hungary); 6) Underside of the specimen shown in picture 4.

\section{Irodalom - Literature}

Fazekas I. 1986: Die Spialia-Arten des Karpatenbeckens und ihre Verbreitung (Lepidoptera: Hesperiidae). - Nachrichten des entomologischen Vereins Apollo 1986; 7 (2/3): 49-55.

Gergely P., Gór Á., Hudák T., Ilonczai Z. \& Szombathelyi E. 2018: Nappali lepkéink. Határozó terepre és természetfotókhoz. - Kitaibel Kiadó, Biatorbágy, pp. 23-69.

Gibbons R. 2021: http://www.butterfliesoffrance.com (visited 20.02. 2021) 
Gozmány L. 1968: Nappali lepkék - Diurna. Magyarország állatvilága - XVI. Akadémiai Kiadó, Budapest, pp. 12-13.

Haahtela T., Saarinen K., Ojalainen P. \& Aarnio H. 2011: Butterflies of Britain and Europe. A photographic guide. - A \& C Black, London, pp. 19-20.

Höttinger H. 2001: Spialia orbifer (Hübner, 1823) in Niederösterreich (Lepidoptera: Hesperiidae). - Beiträge zur Entomofaunistik 2: 55-59.

Lafranchis T. 2004: Butterflies of Europe. - Diatheo, Paris, pp. 22-23.

Lorkovic Z. 1973: 150 Jahre bis zur Entdeckung der präimaginalen Stadien von Spialia orbifer HBN. (Lepid., Hesperiidae). - Acta Entomologica Jugoslavica 9 (1-2): 6770 .

Macek J., Lastuvka Z., Benes J. \& Traxler L. 2015: Motýli a housenky středni Evropy V. Denni motýli. - Academia, Praha, pp. 160-161.

Rákosy L. 2013: Fluturii diurni din Romania. - Mega, Cluj-Napoca, 285 p.

Rowlings M. 2021: EuroButterflies. http://www.eurobutterflies.com (visited 20.02. 2021)

Sáfián Sz., Hadarics T., Szegedi B. \& Horváth A. 2006: Ritka lepkefajok (Lepidoptera) előfordulási adatai egy Fertőrákos melletti mészkőbányából. - Szélkiáltó 12:28-32.

Slamka F. 2004: Die Tagfalter Mitteleuropas - östlicher Teil. - Frantisek Slamka, 2004, pp. 23-25.

Szabóky Cs. 2020: Magyarország védett lepkéi I-II. - Orbiculosa Kiadó, Érd, pp. 182185.

Tolman T. \& Lewington R. 1997: Collins Butterfly Guide. - Collins, London, pp. 334335.

Tóth B. 2019: Magyarország nagylepkéinek határozója. - Magyar Biológiai Társaság, Budapest, $316 \mathrm{p}$.

Varga Z. 1989: Lepkék (Lepidoptera). In: Rakonczay Z. (szerk.): - Vörös Könyv. Akadémiai Kiadó, Budapest, pp. 188-244. 